Voix et Images

voixetimages

\title{
Une image lui bloquait la vue
}

\section{Lucie Lequin}

Volume 19, numéro 3 (57), printemps 1994

Science et fiction au Québec : L'émergence d'un savoir

URI : https://id.erudit.org/iderudit/201126ar

DOI : https://doi.org/10.7202/201126ar

Aller au sommaire du numéro

Éditeur(s)

Université du Québec à Montréal

ISSN

0318-9201 (imprimé)

1705-933X (numérique)

Découvrir la revue

Citer cet article

Lequin, L. (1994). Une image lui bloquait la vue. Voix et Images, 19(3), 649-654.

https://doi.org/10.7202/201126ar d'utilisation que vous pouvez consulter en ligne.

https://apropos.erudit.org/fr/usagers/politique-dutilisation/ 
Roman

\section{Une image lui bloquait la vue}

\section{Lucie Lequin, Université Concordia}

Lire ensemble quatre auteures aussi dissemblables que le sont Claire Dé, Diane Giguère, Élise Turcotte et Josée Yvon rapproche des univers qui, normalement, ne se juxtaposent pas. Pourtant, chaque auteure rend compte de l'amour ou de son absence, de l'abandon et du besoin de s'éprouver vivante, à tout prix, dans l'émotion vive de la vie comme dans la force de l'horreur.

Marie, la narratrice de Caravane ${ }^{1}$, apprend que son amant l'a trompée: "J'ai compris qu'il avait fait l'amour avec elle peu de temps avant et cette image me bloquait la vue" (p. 133). Ces mots d'Élise Turcotte, une image bloquant la vue, pourraient, étonnamment, entretisser et expliquer chacune des ouvres; l'image bloquant la vue, l'image à décanter, à éloigner, l'image à dire ou à crier afin de vivre, de survivre même, devient l'œuvre à écrire ou empêche l'œuvre de s'écrire.

Marie, dans Caravane, regarde entre deux lames de store vénitien et "fabrique des images dans [sa] tête" (p. 153). Dès images au ras d'un quotidien chargé d'émotions, des images qui permettent d'accéder à une conscience aiguë des choses et qui explorent la vie et l'écriture, des images où l'on respire encore. Dans Sourdes Amours $^{2}$ de Claire Dé, la narratrice "je" se laisse pétrifier par un cheveu trouvé sous le traversin; Claire Dé donne à lire l'impact de cette image qui, immédiatement s'installe, obsède la narratrice et l'emprisonne encore davantage dans un amour inutile. L'Abandon ${ }^{3}$, le dernier roman de Diane Giguère, publié plus de quinze ans après Dans les ailes $d u$ vent (1976), réunit deux image d'un même papillon: l'une merveilleuse de beauté; l'autre monstrueuse, chargée de danger, voire de mort. Deux êtres écorchés, la narratrice Muriel et Johnny, se croisent le temps d'un été et se réfugient dans l'amour, un amour rapide et excessif. Avec La Cobaye ${ }^{4}$, Josée Yvon dessine des images d'horreur: euthanasie à l'alcool ou aux court-circuits de "rushs" (p. 88) dans les veines; danseuses androgynes, nues dans des cages, scènes sadiques qui aboutissent au meurtre, haine cultivée, dévorante, pour maintenir le bon dosage de "raison-convulsion-destruction" (p. 49); acide, téléphone cellulaire, gaz d'oxyde nitreux, lecteur optique... résument 
l'univers des femmes sans avenir, dépossédées, exaspérées, que décrit Josée Yvon; un univers étouffant, effroyable où tout se vend.

$$
\text { ** }
$$

La prose de Josée Yvon s'inspire du cri de révolte, le lexique est cru et les émotions, brutes. Cette écrivaine poursuit, dans son quatorzième livre, son exploration de la violence et de la mort. Persuadée que la vie n'est qu'un champ de bataille, que seule une plongée plus profonde dans la laideur donne encore l'impression de vivre, elle n'épargne rien ni personne. Elle se moque d'ailleurs de l'écriture, peut-être de son œuvre même; Tava, une poète, s'attache à Threesa, une mercenaire expulsée de l'armée pour alcoolisme. La poète veut écrire un livre sur cette soldate qui n'a rien à dire et ne croit surtout pas à l'écriture; Tava cherche en cette femme "un sujet féminin plausible, original. Les deux ne cherchent qu'à voler. Et les deux n'y gagneront que quelques bribes" (p. 96). La poète croit encore à la vie, au pouvoir des mots, à la complicité et à l'amour. Elle héberge donc des amies de Threesa et au printemps, l'une d'elles la tuera, comme quoi il ne faut jamais croire en rien.

Ce clin d'oeil à l'écriture parodie certes la problématique de l'écriture au féminin et de l'écrivaine à l'affût du féminin; de plus, la quatrième de couverture comporte une allusion au premier roman d'Élise Turcotte: "Poursuivant son projet de dire plus que le bruissement des choses vivantes, Josée Yvon...", mais c'est aussi une mise en doute du projet même de Josée Yvon qui veut écrire la violence de cette Amérique composée de cowboys et de sauvagesses, qui veut donner la parole à des amazones cobayes qui n'y croient plus, qui ne pensent qu'à la torture, à la drogue et à l'alcool. La société apocalyptique que décrit Josée Yvon ne réserve aucune place à la création, à moins qu'elle ne soit monnayable. Le cri est-il audible dans un univers d'où le silence créateur s'est enfui? Y reste-t-il des choses vivantes, des êtres vivants dont on pourrait entendre même un bruissement?

Josée Yvon s'acharne à décrire un univers agonisant, sans lois et sans amour, où rien ne compte; il y a peu de surprises dans ce dernier livre qui reprend les préoccupations de l'auteure. Pourtant, même si par sa critique de l'écriture, elle clame haut et fort l'impossibilité ou l'inutilité de dire le désespoir, le monde étant irrémédiablement clos, Josée Yvon, elle, écrit et le dit: "Il faut toujours le vivre et l'écrire comme si on allait mourir exactement"(p. 110). Elle écrit ses images du Mal lui bloquant la vue. 
L'Abandon de Diane Giguère dit d'une autre façon le Mal contemporain. Muriel souffre du départ d'Endre, rentré en Europe de l'Est participer aux événements qui ont entraîné l'effondrement du régime communiste. Le roman se termine d'ailleurs à ce moment-là. Endre n'est présent dans le roman qu'en différé, lorsque Muriel se rappelle leur liaison; enfant, il n'a fait qu'entrevoir son père qui était ou en prison en Sibérie, ou caché à cause de ses activités clandestines; cette "blessure de l'enfance" (p. 10), cette absence du père, sous-tend la vie adulte d'Endre, son travail créateur, son "théâtre d'ombre" (p. 10). Lorsque la vie politique bouge dans les pays communistes, il doit partir combler l'abandon qu'il n'a jamais pu contourner. Impuissante à oublier cet amour perdu, Muriel s'enferme dans la solitude, mais s'ouvre également sur les souffrances intimes générées par des drames publics et politiques.

Le dimanche, elle quitte la ville pour aller se replonger dans la Vallée de la Rouge, région de ses amours, où elle peint le paysage à la fois enchanteur et désolé. Elle y rencontre Johnny, hanté par une guerre qu'il ne peut oublier. Muriel sent le trouble de Johnny, l'ombre qui l'entoure, mais le désir de vivre un amour, même fugitif, l'emporte sur le risque d'être à nouveau abandonnée.

Pour comprendre Johnny, Muriel se met à lire des livres sur la guerre du Viêt-nam, les résume, les complète de ses conversations avec son amant. C'est là que L'Abandon prend son sens; Diane Giguère veut moins montrer les troubles de l'âme amoureuse que les drames humains traversant l'histoire depuis toujours. C'est aussi, je crois, la faiblesse du roman, car ce discours informatif sur la guerre du Viêt-nam avec références à l'appui - plusieurs ouvrages sont cités ou sur la libération de prisonniers de camps de Sibérie ou de prisonniers coréens détenus depuis la Seconde Guerre mondiale (p. 105), brise la trame romanesque. Muriel, Johnny ou Endre ne deviennent alors que des prétextes pour s'interroger sur la civilisation planétaire du mensonge; les autorités politiques, peu importe le lieu, manipulent l'opinion publique, préfèrent déclarer mort un soldat disparu ou un prisonnier, par exemple, pour ne pas révéler les failles ou les abus de leur armée; elles ne veulent pas de témoins gênants.

Lorsque Johnny disparaîtra soudainement de la vie de Muriel, elle saura même avant de lire le manuscrit qu'il a laissé, qu'il est l'un de ces témoins gênants. Elle tentera de le retracer, mais comme pour Endre, elle ne le pourra pas. De ces deux amours, il lui restera une 
conscience politique plus grande et une meilleure compréhension de l'immense souffrance et de l'impossible repos de l'être victime de l'Histoire. Selon Muriel, et peut-être Diane Giguère: "Et qu'est-ce que le pays sans l'amour, oui, sans ce refuge contre l'histoire qui n'est qu'un jeu incessant de réfection et de destruction?" (p. 60). Refuge bien éphémère et bien fragile, puisqu'à la fin, Muriel se retrouve à nouveau seule, dans le silence et l'abandon, et l'homme - Johnny et Endre -, repris par l'Histoire.

Ce dernier roman de Diane Giguère donne de belles pages denses sur la Vallée de la Rouge, sur ce papillon mystérieux qui relie le présent et le passé, l'histoire de Muriel et celle de Johnny, la représentation de la beauté et celle de la laideur. Ailleurs, il manque de densité, d'épaisseur. Le discours informatif éclaire trop l'ombre et l'énigme, la nouvelle conscience humaniste à transmettre bloque la visée romanesque et le journal de Muriel ressort parfois de l'écriture journalistique.

\section{**}

Sourdes Amours s'inscrit aussi dans les préoccupations actuelles: maladie d'Alzheimer, insurrection roumaine, nouvelles relations de couples, exil, mais seul compte l'amour de la narratrice pour un homme qui ne l'aime plus. En écho à la douleur du "je", les drames de Vassilissa et de Monique F. qui, elles aussi, vivent mal leur couple moderne respectif "qui ne se marche pas sur les. Dans lequel chacun dispose de tout son" (p. 63). Sourdes Amours se veut donc aussi un regard acidulé et instantané sur l'amour où le désir a été assassiné.

L'intrigue se déroule à Paris, mais le "je " de la narration est originaire de Novossibirsk et écoute Daniel Lavoie et Diane Dufresne. Cette narratrice anonyme doute de la fidélité de son mari; elle, qui avait toujours affirmé que l'amour était un "dérangement inutile" (p. 79), s'engage auprès de cet homme, l'épouse même, alors que, déjà il est lointain, lassé d'elle qui ne le délasse plus. Lui ne supporte pas l'amour au quotidien, tout est dans la conquête, elle ne conjugue l'amour qu'au présent, attend tout de l'amour: "Je t'attendais. Et t'attendrais, beaucoup plus tard, beaucoup plus. En vain. Je t'attends. J'attends tes lèvres sur mes lèvres, sur moi, tes mains. Ton sexe" (p. 83). Une brèche entre eux, un amour échiffé, elle le sait mais s'accroche, dégringole et dépérit; elle accepte même de partager leur appartement avec Rosemonde, l'une des amantes du mari. Si, à la fin, elle le quitte, c'est qu'elle craint de finir comme Vassilissa, une amie de jeunesse, qui vient de se suicider. Elle "s'arrache" (p. 98) plutôt qu'elle ne part. 
Une histoire d'amour et de mensonges, somme toute, très courante: palpitations d'un cœur emprisonné et amer campari. Pourtant, ce roman de Claire Dé retient l'attention. Le récit de cet amour absurde s'avère efficace; l'amour, le désir, l'infidélité, l'avilissement ne sont que nommés, d'allusions en allusions, à demi-mots, dans des phrases brisées, la narratrice ne se rend pas au bout de sa pensée, au fond, ne laisse pas l'intellect intervenir. Les rares occasions où c'est la pensée qui agit - une lettre de rupture, par exemple - les phrases sont complètes et l'analyse, claire. Les sourdes amours de ce "je" morcèlent, l'entraînent loin d'elle-même, la placent en rupture d'elle, l'emprisonnent. Les phrases brisées traduisent ce dérangement intérieur. L'image du cheveu trouvé au début du roman prépare la rupture finale comme s'il fallait que la narratrice sombre un peu plus loin dans la servitude du cœur, quasi masochiste, afin d'accumuler lentement les forces qui l'éloigneront de son amour inutile. Plus rien ne lui bloque alors la vue.

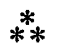

Caravane réunit quinze nouvelles, quinze histoires de Marie, "quinze chapitres de son abandon, comme elle dit" (p. 9). Mis à part le quinzième texte "Lettres à personne", les regards de Marie sur le monde extérieur s'organisent autour de deux thèmes: "Abandon" et "Vigilance". Mais ce qui ressort de ce recueil, c'est une impression d'unité. Marie perd pied dans les images et le raconte. Sensible au pouvoir du langage, des rêves et des choses, elle ne voit pas la vie comme les autres. Dans "Comment vivre le soir de son anniversaire", elle soumet un homme à son monde d'images dont elle explique l'effet : "C'est un bomme égaré. J'avais réussi à perdre un homme, à l'éloigner de lui-même pendant quelques heures et c'est exactement cela qui faisait circuler l'allégresse en moi " (p. 77). Des images donc pour transporter, éloigner, faire voir le geste humain qu'on ne voit plus, des images à habiter seule, à partager parfois.

C'est par le regard surtout que les images du quotidien rejoignent Marie, images qu'elle veut entendre respirer. La carte de visite d'une mère indifférente, les passagers du métro, une vieille femme qui a du mal à descendre l'escalier, une petite famille heureuse, un air de musique, tout se transforme en image à approfondir; les images l'assaillent, puis s'estompent, mais laissent rarement Marie tranquille. C'est au fond la gestation des images qu'Élise Turcotte tente d'appréhender: "Si une femme trébuche devant ma fenêtre, son geste finit par voler 
dans la maison, autour de moi, essayant de former une âme" (p. 80). Lorsqu'elle ne peut passer outre, Marie monte dans la caravane perdue regarder, écouter et écrire afin de ne pas rester "une femme prise en dehors d'elle-même" (p. 43).

C'est également la force des émotions qu'Élise Turcotte explore dans ses nouvelles. La peur, le silence, la tristesse, l'amitié, l'amour se conjuguent pour créer l'espace d'où elle écrit, un espace inouï où, dans l'ombre, affleure la solitude permettant d'accueillir les images à interpréter. À partir de la photo d'un petit camion jaune, "L'avenir de ma solitude" narre ce processus de l'écriture: "Je devais partir, retrouver cette route pour qu'il n'y ait plus de distinction entre le drame et le paysage, entre le paysage et moi (p. 157).

Caravane donne à lire des émotions vives, fait entendre une musique claire et juste où l'on sent la main de la poète. C'est aussi l'écriture en représentation et en images. Images tristes, mais aussi souvent, "un pur ravissement" (p. 167).

1. Élise Turcotte, Caravane, Montréal, Leméac, 1994, 167 p.

2. Claire Dé, Sourdes Amours, Montréal, XYZ éditeur, coll. *Romanichels *, 1993, 98 p.

3. Diane Giguère, L'Abandon, Montréal, Pierre Tisseyre, 1993, 129 p.

4. Josée Yvon, La Cobaye, Montréal, VLB éditeur, 1993, 111 p. 